\title{
ON THE GRAMMATICALIZATION OF AS WELL AS IN THE HISTORY OF ENGLISH
}

\begin{abstract}
The English language as it is known today has undergone a number of developments that have changed it throughout time. Among them, grammaticalization stands out because of its relevance in the progress of the language, as it consists in the process by which a lexical word having full meaning becomes a grammatical item. The present paper analyses the process of grammaticalization of the quasi-coordinator as well as in order to ascertain its origin and describe its developmental path, identify the linguistic causes that motivated the change, propose a functional taxonomy of the construction, and evaluate the influence of sociolinguistic factors in the development and standardization of the quasi-coordinator.
\end{abstract}

Keywords

Grammaticalization; as well as; quasi-coordinator; reanalysis; semantic bleaching; diachronic study

\section{Introduction}

Coordination is defined as the connection between two or more elements with syntactic symmetry in the sense that they belong to the same category with an equal status within the sentence and, in most of the cases, their order is interchangeable (Huddleston et al. 2002). These coordinate sentences are generally linked by the coordinators and, or, and but, expressing conjunctive, disjunctive, and adversative coordination, respectively. Coordinate sentences, however, do not always present a defined structure, varying according to the presence or absence of the coordinator, thus classified as syndetic (e.g. he invited all his 
colleagues and all his students) or asyndetic (e.g. he invited all his colleagues, all his students) (Huddleston and Pullum 2002: 1276). The present study is then concerned with syndetic coordination where an explicit connector appears.

Syndetic coordination, in turn, is observed to have different syntactic roles, linkers behave either as coordinators or subordinators depending on context as shown in instances (1-2) below, in which Quirk et al. (1985: 982-983) illustrate this syntactic flexibility with the connector rather than insofar as it may embody both coordinating and subordinating relations:

\section{(1) He is to be pitied rather than to be disliked}

\section{(2) Rather than cause trouble, I'm going to forget the whole affair}

In the light of this dual function, the term quasi-coordinator has been coined to refer to this particular type of connectors. Following this thread, together with and along with may also be taken as expressions of addition sharing these dual functions in such a way that they may appear not only clause-initially but also heading a prepositional phrase (Huddleston et al. 2002). As well as, in turn, is in comparison a more versatile construction in the sense that it is also used as a) an adverb of manner; $b$ ) a grammaticalized coordinator sharing the same function as the conjunction and; and c) an adjunct introducing a subordinate clause, as shown in examples (3-5).

\section{(3) I played as well as I could}

(4) England as well as Scotland are part of the United Kingdom

(5) He bought the piano as well as his friend did the previous week

This flexibility of quasi-coordinators is sometimes taken as a violation of rules. Forbes (2014), among others, studied the status of the quasi-coordinator gan in the indigenous language Gitksan, suggesting that it stems from a breach of Ross' Coordinate Structure Constraint Rule (1967). In the light of this rule, "no conjunct may be moved, nor may any element contained in a conjunct be moved out of the construction" (1967: 89). Thus, it is claimed that quasi-coordinators such as as well as and rather than break the adjacency rule by placing the more distant clause from the main verb as the head of the coordinated subject (Kim 2002). This feature is illustrated in example (6), where the verbal agreement is made between the verb and the teacher:

(6) The teacher as well as the students was tired

On historical grounds, compound sentences are observed to behave differently in the earlier stages of English. In early Modern English, subordination is assumed to outnumber coordination as a result of the influence of classical rhetoric in the 
sense that "[s]ubordination is typical of the sentences imitating the Ciceronian period, coordination of sentences written in "the Senecan style" (Rissanen 1999: 280). ${ }^{1}$ Kohnen (2007: 294), in his analysis of the distribution of coordinators and subordinators in a compilation of Middle English and early Modern English sermons, has noticed that while the rate of coordinators is observed to decrease significantly in the period under scrutiny (especially from the $16^{\text {th }}$ century), there is a significant increase of subordinators. This attitude may be interpreted in view of the fact that literacy increased in the early Modern English period, thus giving room to the on-going diffusion of mechanisms intrinsically connected with the written domain (subordination in particular).

Despite the wider distribution of subordination in the period, coordination was not obliterated whatsoever. Even though it is a fact that asyndetic coordination progressively lost much of its relevance, syndetic coordination gained substantial ground as a result of the increase of standardization in early Modern English writings. ${ }^{2}$ The dissemination of and in different environments, for instance, was often deemed to be ambiguous since it headed both concessive and conditional clauses regarded as subordinate today (Rissanen 1999).

The process of grammaticalization of many of these quasi-coordinators has been virtually neglected in the literature and, in the particular case of as well as, its diachronic development is still unexplored. The present paper, therefore, studies the process of grammaticalization of this quasi-coordinator, examining the syntactic and semantic changes of the construction over time with the following objectives: a) to ascertain its origin, examining the linguistic causes that motivated the change, both syntactically and semantically; b) to describe its grammaticalization path; c) to propose a functional taxonomy of the construction; and d) to assess the participation of sociolinguistic factors in the development and eventual standardization of the quasi-coordinating construction.

\section{Corpus and methodology}

The source of evidence for the present study comes from two different corpora: the Helsinki Corpus of English Texts (henceforth HC) and the Parsed Corpus of Early English Correspondence (henceforth PCEEC).

The $\mathrm{HC}$ is a multi-genre diachronic corpus covering from the $8^{\text {th }}$ to the $18^{\text {th }}$ centuries. The corpus is composed of c. 1.5 million words divided into 403 samples from three different historical periods: Old English, Middle English, and early Modern English, the first and the second divided into subperiods of 100 years, and the third classified into subperiods of 70 years, for the sake of diachronic comparison. ${ }^{3}$ Moreover, every sample is provided with data about the text and its author, making the corpus suitable for sociohistorical studies.

The PCEEC covers the historical period 1410-1681. Released in 2006, the corpus is available for the user in three versions: plain text files, POS-tagged files, and syntactically-parsed files. The POS-tagged version of the corpus has 
been used in this study, containing approximately 2.2 million words divided into 4,970 letters belonging to 84 letter collections. Even though an excellent source for sociolinguistic analysis, it is not balanced insofar as only a fifth of the informants are women, while the upper social classes become more widely represented due to the illiteracy of the lower classes. In spite of this, this corpus stands out for being a reliable input for the quantitative and sociolinguistic dimension of a construction over time. The letters, regarded as a genre closely mirroring the oral language of the period, facilitate an approach to the spoken register and allow a sociolinguistic study considering variables such as social status, gender, age, and education, among others (Vázquez et al. 2011; Conde-Silvestre and CalleMartín 2015).

The software AntConc 3.4.3 has been used for the automatic retrieval of the instances. The process, however, has not been straightforward. Multiple searches have been carried out depending on the corpus, whether the POS-tagged or plaintext files. Firstly, the list of adverbs in the PCEEC corpus was retrieved using the corresponding wildcard for this grammatical category, * ADV, where manual disambiguation was needed to rule out the instances beyond the scope of the present study in the cases of the adverbs welbeloued, whellfauryd, etc. The process was more complex with the $\mathrm{HC}$ based on the orthographic and intra-dialectal variation of the string, i.e. swa wel swa, as wel as, as wele as, as weel as, as weele as, as whell as, as wal as, as will as, as wyll as, etc. It goes without saying that further disambiguation was needed to disregard those instances where the sequence does not strictly function as a conjunction. All in all, the present study is based on a total of 560 instances of the quasi-coordinator as well as, of which 182 belong to the $\mathrm{HC}$ and 378 to the PCEEC corpus.

\section{Grammaticalization}

\subsection{Historical approach}

Grammaticalization is the process by which a lexical word having full meaning becomes a grammatical item (Fischer et al. 2000). In the last years, two major approaches to grammaticalization have developed according to how grammar is conceptualized. The first focuses on reduction and increased dependency, whilst the second on different types of expansion (Traugott 2010). The traditional approach regards grammaticalization as a form of reduction, which involves a loss of autonomy and more constrains to linguistic rules, that is, stronger internal dependencies (Lehmann 2004; Haspelmath 2004). The second approach, in turn, views grammaticalization as involving structural expansion. Three types of expansion are distinguished by Himelmann (2004): a) host-class expansion; b) syntactic expansion; and c) semantic-pragmatic expansion. In this light, grammatical constructions become more abstract and productive, with mechanisms and processes such as reanalysis and decategorialization playing an important role in 
grammaticalization processes. This approach regards unidirectionality as a central hypothesis, as it considers grammaticalization to move in a path of structural properties, from lexical to grammatical or from less to more grammatical, thence regarded as an irreversible process.

The second approach is adopted in the present study, examining the grammaticalization of as well as as a process of structural expansion. This analysis is carried out from a diachronic viewpoint in view of the fact that "grammaticalization theory is concerned with the genesis and development of grammatical forms" (Heine and Song 2011: 590), pursuing the study of the origin and development of new structures and their causes. The following sections then deal with a historical approach of the quasi-coordinator in order to ascertain its origin and describe its grammaticalization path. A quantitative analysis is also carried out to examine the distribution and diffusion of as well as and propose a functional taxonomy of the construction relying on the categorization provided by the Oxford English Dictionary (henceforth OED) (Simpson and Weiner 1989).

The grammaticalization process of as well as is taken to undergo the following stages of development: well > as well > as well as. In the light of this trend, this quasi-coordinator originally stems from well, which functions as an adverb and an adjective on the propositional level, or as a discourse marker on the textual and interpersonal levels (Jucker 1997). This connector comes from the Old English adverb wel, with two basic meanings according to the OED, i.e. 'in accordance with a good or high standard of conduct or morality; in a way which is morally good' and 'satisfactorily in respect of conduct or action', as shown in examples (7-8):

(7) it shal doo weel, with God is grace, hoo haue yow in kepyng and all youres $[\ldots]$

(PCEEC, John Bokking, 1456)

(8) used them so well and graciously that he sent both parties away well pleased $[\ldots]$

(PCEEC, Thomas Cromwell, 1538)

A new form already emerged in the Old English period as a result of its combination with swa, giving way to the sentence adverbial as well. In the particular case at hand, a class-internal adverb developed into a sentence adverbial, preserving the same syntactic category after a sequence of internal changes. The construction is first immersed in a process of semantic bleaching according to which there is a loss of semantic content from a concrete to a more abstract or general meaning, i.e. 'also, in addition, or in the same way' (OED). As a result, the adverb increased its productivity, appearing in a wider range of contexts as shown in (9), where swa wel (as well) allows the connection of two sentence elements, becoming complementary. The two adverbial forms, well and as well, have coexisted in English since then. 
(9) hade nateshwon becuman buton of Aarones cynne, pæs forman bisceopes, be godes gesetnysse. Hit mihte pa swa wel beon, forpam pe hi ne mæssodon næfre $[\ldots]$

(HC, Aelfric, 950-1050)

The late Old English period also witnessed the coining of a new form by the inclusion of the adverb swa, giving rise to swa wel(l) swa (as well as). The earliest instance of this construction has been dated back to c. 950-1050 in the HC. This development is explained in terms of an additional step in the process of grammaticalization. Initially, swa wel(l) swa is observed to convey the meaning of 'as good, satisfactory, a way or manner as', where wel(l) still behaves as an adverb of manner. Next, swa wel(l) swa is also normally accompanied by the sequence pronoun + best + verb, or even by an auxiliary verb such as could or should. It is in this particular environment where swa wel(l) swa is found to connect clauses instead of independent lexical words.

Two paths of grammaticalization are then distinguished, from lexical to grammatical, on the one hand, and from less to more grammatical, on the other. According to the scale of grammaticality, the construction as well as undergoes the first type of development becoming a conjunction, deprived of its adverbial function. In this same vein, Giacalonet-Ramat and Mauri's classification of conjunctives (2011) considers as well as as a focal-additive particle. Conjunctive connectives generally arise from spatio-temporal adverbs and prepositions, where a process of abstraction is assumed. The case of as well as however is slightly different in the light of its particular development, as it originates from an adverb of manner instead of a spatio-temporal adverb.

(10) pæt is his clænnese \& munuclice scrudware \& peowian his Drihtne, swa wel swa he betst mæge

(HC, Aethelred, 950-1050)

Swa wel(l) swa developed, however, more than one meaning after its conception. First, the construction acquired a comparative function to contrast two elements with the sense of 'in the same degree, as much as' (OED). The earliest instance of this meaning is traced back to the period 950-1050 in the HC. Second, it also became a conjunction after a process of decategorialization which eventually limited the syntactic freedom of the structure, being compulsorily placed between the NPs or VPs involved. This decategorization is characterized by the following features listed by Heine and Song (2011): a) the loss of the capacity to be inflected; b) the loss of the faculty to assume derivational morphology or modifiers; c) the increasing dependence on other elements; d) the impossibility to co-occur with members of the same grammatical category; and e) the loss of anaphoric reference. On semantic grounds, swa wel(l) swa also undergoes a process of gradual desemanticization according to which well is bleached losing its adverbial meaning. This results in an abstraction of concepts and a variation of 
context, from those implying actions performed by human beings (e.g. as well as he knows) to those denoting a comparison between two elements or actions.

(11) And gif pu woldest me lufian and to minum godum pe gebiddan, be sceolde beon eall swa wel, eall swa me selfan

(HC, St. Margoe, 1050-1150)

In the late $14^{\text {th }}$ century, the conjunction as well as adopted a new coordinating function in order to connect two ideas with the same status. Two principal meanings can be here distinguished. On the one hand, as well as is used as an equivalent to 'both... and, not only... but also' (OED). On the other, it denotes the inclusion of one element to the sentence, both meanings represented in examples (12) and (13), respectively.

(12) And God dide awei al substaunce that was on erthe, fro man til to beeste, as wel a crepynge beeste as the briddis of heuene

(HC, Genesis IX. 29, 1384)

(13) havyng awey specialy of the Duc of Orlians, and also of the king as welle as of the remanant of my forsayd prysoners that god do defende

(PCEEC, Henry V Signet, 1419)

In example (12), both the crepynge beeste and the briddis of heuene are at the same syntactic level as happens in (13) with the prepositional phrases of the king and of the remanant of my forsayd prysoners. Thus, this conjunction develops from the comparison of two elements in a sentence to the expression of their coordinate function, and as such it is positioned between two phrases with the same category. Nevertheless, its representation varies at the surface structure level depending on its meaning. When the construction means 'both... and', the construction is split as follows: 'as well + clause + as + clause'. In this pattern, as well as is mainly located between two PPs or two NPs, although it is at times placed between two AdjPs. When this conjunction is used to introduce another element in the sentence, on the other hand, it is consistently represented as a single unit, normally placed between two PPs (introduced by the prepositions of, by, to and for), two NPs, or occasionally between two VPs: 'clause + as well as + clause'.

This development is the result of reanalysis, one of the main mechanisms in grammaticalization theory, defined by Langacker (1977: 58) as "[a] change in the structure of an expression or class of expressions that does not involve any immediate or intrinsic modification of its surface manifestation". Reanalysis involves metaphorical change, which is a "linear, syntagmatic, often local, reorganization and rule change" (Hopper and Traugott 2003: 68). This process entails the rebracketing of the sentences as shown in examples (14-16): 
(14) they must redeeme themselves as well as they can

(PCEEC, John Chamberlain, 1613)

(15) I might have been at home all this while [as well as] heer

(PCEEC, Thomas Knyvett, 1625)

(16) I gladly kissed the outside [as well as] the inside of your letter (PCEEC, Thomas Meautys, 1630)

The grammaticalization process of the conjunction as well as is illustrated in examples (14-16). While in (14) well behaves as an adverb of manner; in (15) as well as functions as a conjunction to imply a comparison between two elements, where well has completely lost its adverbial role, thus deprived of its lexical meaning. In (16), in turn, as well as has become a coordinator resulting in the association of two items. This coordinator can be twofoldly rendered, either as a single unit as in (16) or split into two units, in which case its function is not altered and it may be reordered without any semantic change:

(17) the care will requyre as well bodily as spirituall phisick

(PCEEC, James Harrison, 1630)

This sentence may then be reformulated as the care will requyre bodily as well as spirituall phisick without any functional or semantic change. In addition to this, the previous instances present one characteristic of grammaticalization: the layering of meanings from a synchronic point of view. The chronological progress of as well as and the multiple meanings that have emerged over time reveals the coexistence of meanings in the process, while none of them disappeared with the emergence of the other.

After this process of grammaticalization, as well as can be deemed as a quasicoordinator behaving either as a subordinator or a preposition. As a coordinator, it must be compulsorily placed between the two statements. As a subordinator, however, it can be placed in front position, inheriting the flexibility of adverbials, its original syntactic category. Thus, Quirk et al. (1985) measures the quasicoordinator as well as between coordinators and prepositions. For example, in (16), as well as behaves as a coordinator between two NPs, but it can be moved to front position acquiring a subordinating role as in (18):

(18) as well as the inside of your letter, I gladly kissed the outside

All in all, three types of expansions identified by Himmelmann (2004) have been ascertained in the grammaticalization of as well as: a) host-class expansion, by which a grammaticalized item extends its range of co-occurrence with the different syntactic categories, entailing an increase of productivity; b) syntactic context expansion, by which the new form appears in a wider variety of contexts; and 
c) semantic-pragmatic expansion, by which the term develops new meanings in certain contexts.

\subsection{Quantitative analysis}

In the light of the development of this quasi-coordinator, it is used with four different senses according to the OED: (a) 'in as good, efficient, satisfactory, (etc.) a way or manner as'; (b) 'to the same extent, in the same degree, as much, as'; (c) 'with weakened force, passing into the sense of both... and, not only... but also'; and (d) 'used to denote the inclusion of one thing (person, etc.) or class with another'. Their use and diffusion over time is reproduced in figures 1 and 2, albeit the periods 1150-1250 and 1250-1350 are omitted in this analysis due to the scarcity of data. For the sake of comparison, frequencies have been normalized to tokens per 10,000 words.

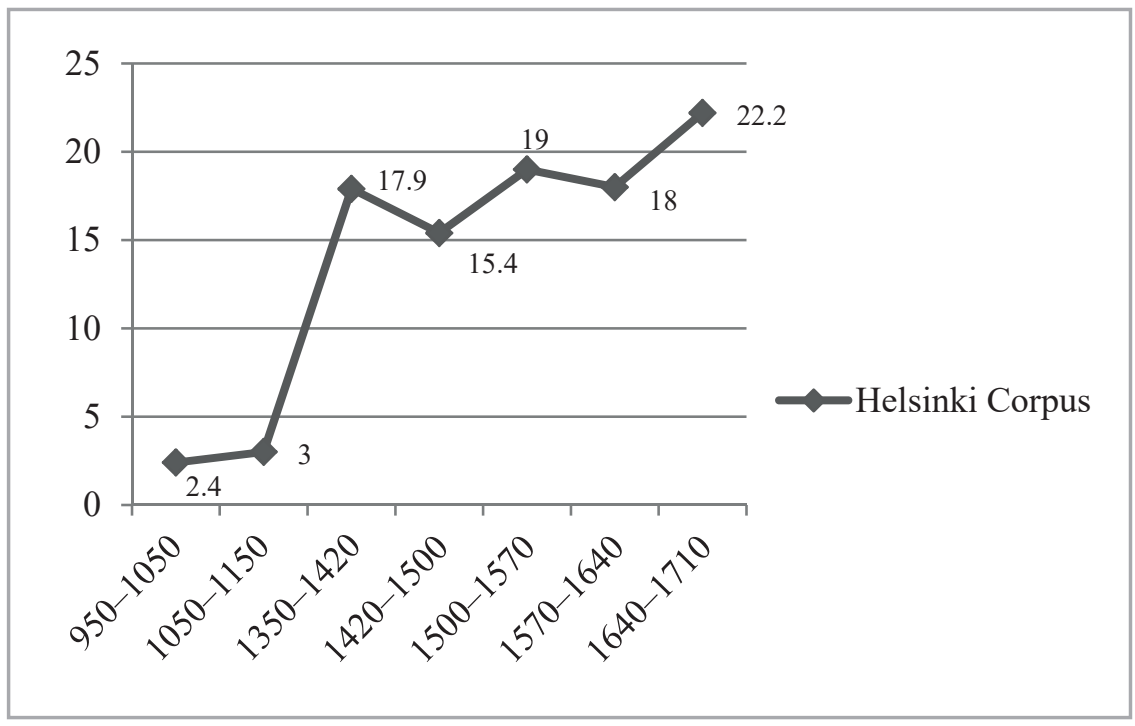

Figure 1. Distribution of as well as over time in the HC (n.f.)

Figure 1 reproduces the development of the conjunction as well as over time. It represents the normalized frequencies of this construction in the $\mathrm{HC}$ between 950 and 1710. The development of as well as becomes evident in this figure, revealing a moderate use after its emergence with a substantial increase in the period 1350-1420, a diffusion which may be interpreted as a result of the development of its new function as a coordinating conjunction. Since then, the dissemination of this quasi-coordinator has unwaveringly risen until the $18^{\text {th }}$ century. 


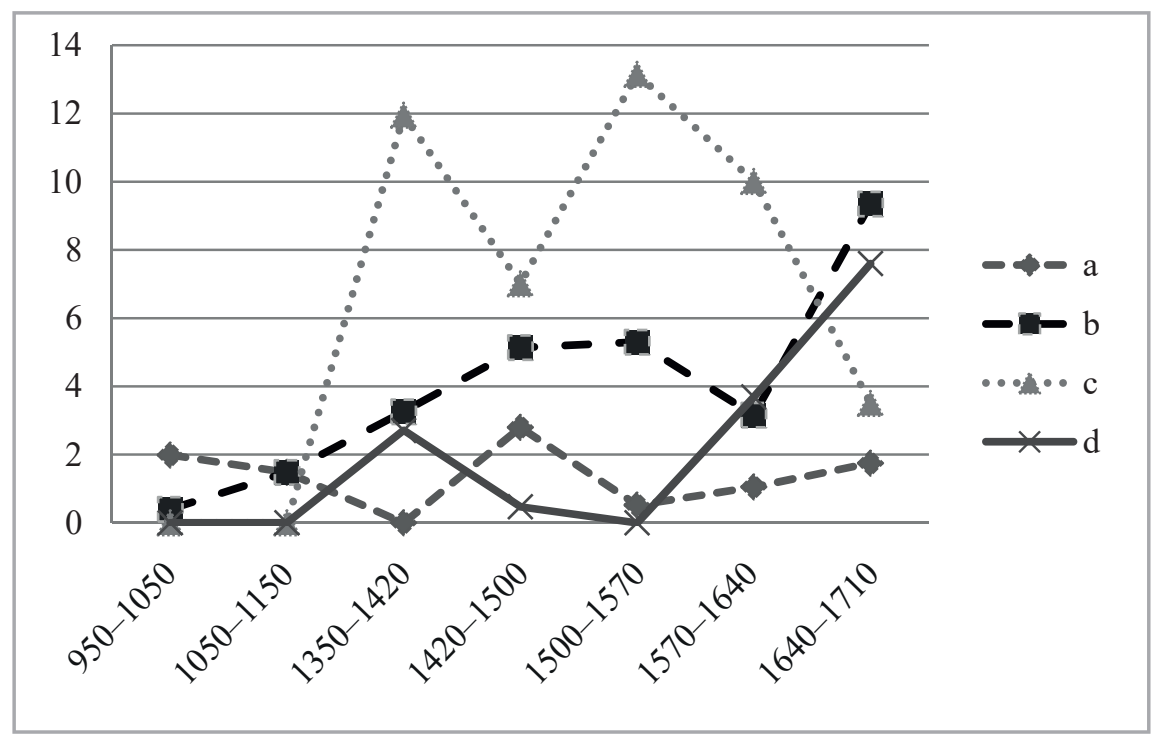

Figure 2. Distribution of as well as according to its taxonomy in the HC (n.f.)

Figure 2 reproduces the occurrence of as well as over time according to its taxonomy of meanings and functions, from 950 to 1710. On historical grounds, the conjunction as well as has progressively developed towards the use of its comparative function (b), coinciding with its decrease as a coordinator after 1570 (c). This tendency rises steadily to such an extent that in the period 1640-1710 it had already outnumbered its use as a coordinator for its comparative function (9.35 and 3.5 in the period 1640-1710). Its decline also coincides with the rise of as well as as a coordinating conjunction introducing a new element in the sentence. This results in a preference for the structure 'clause + as well as + clause' rather than 'as well + clause + as + clause' from the early Modern English period onwards.

\section{Sociolinguistic analysis}

\subsection{Sociolinguistic framework}

The rationale of a historical sociolinguistic analysis lies in the belief that human being behaviour has remained unchanged over time, and that languages have varied in the past in the same way as they do today. Historical sociolinguistics endorses the tenet according to which "the principles governing the world were the same in the past as they are now" (Lass 1997: 25). This considered, it is normally assumed that "social differences between speakers are among the driving forces for the diffusion of new linguistic elements among populations" (Conde-Silvestre and Calle-Martín 2015: 67) and that the connection between social classes and 
linguistic variation today does not differ from the past (Nevalainen and Raumolin-Brunberg 2003).

Bearing this in mind, the diffusion of as well as in early Modern English has been evaluated according to the social stratification of the period in order to identify the social groups leading the diffusion of this quasi-coordinator. Notwithstanding this, historical sociolinguistics should avoid anachronism insofar as societies in the past were divided differently from modern societies (Nevalainen 2012). The concept of class did not exist in the pre-industrial society and the term rank is preferred to single out groups in the past. As Säily (2014) remarks, if society is considered as a group of people sharing their power, political and economic condition, only one class would be recognized before 1800 . Therefore, in present-day sociolinguistic analysis, "the meaning of a variable has to be recovered from the historical text that is the subject of linguistic analysis, as well as from the background writings of the historical period under study" (KiełkiewiczJanowiak 2012: 307).

Several authors have proposed different models as an attempt to reconstruct social stratification in early Modern English. The present study follows the hierarchical division proposed by Nevalainen and Raumolin-Brunberg (1996), representing the rank and status in Tudor and Stuart England, although some modifications have been introduced. Different factors have been considered to allow for the different positions owned by the same person at the same time: lifestyle, legal position, property rights, and social function, among others. This categorization proposes a division between the nobility, the gentry, the professionals, the non-gentry and the clergy, with the upper and lower members of each rank also distinguished. According to the curvilinear hypothesis, this model focuses on the principal social groups considered for the study of linguistic variation (Labov 2001). Our analysis, however, relies on the nobility, the gentry, the clergy, the professionals and the non-gentry, together with the royalty and the merchants, although the latter are not so widely represented. The upper and the lower status of the gentry and the non-gentry have not been considered in the present analysis to avoid any likely misinterpretation of the results. The members of the clergy, in turn, are taken as part of the same social rank, unlike Nevalainen and RaumolinBrunberg's model (1996), which includes them in different social ranks according to their status in society (e.g. archbishops and bishops as members of the nobility). The royalty is taken at the highest position of society, and merchants are not considered as professionals, but an individual rank in itself. Thus, the social stratification used in the present study is classified as followed: 1) Royalty; 2) Nobility; 3) Gentry; 4) Clergy; 5) Professionals; 6) Merchants; and 7) Other non-gentry.

The rationale behind this categorization and the allocation of informants to their corresponding rank rely on the information retrieved from the PCEEC metadata. The social position of informants is provided in the metadata, and it has consequently been categorized according to the social stratification followed in the present paper (Table 1). In this way, Elizabeth Tudor, labelled as Queen of England, is 
Table 1. Social stratification in England in the $15^{\text {th }}-17^{\text {th }}$ centuries (Nevalainen and Raumolin-Brunberg 1996: 26).

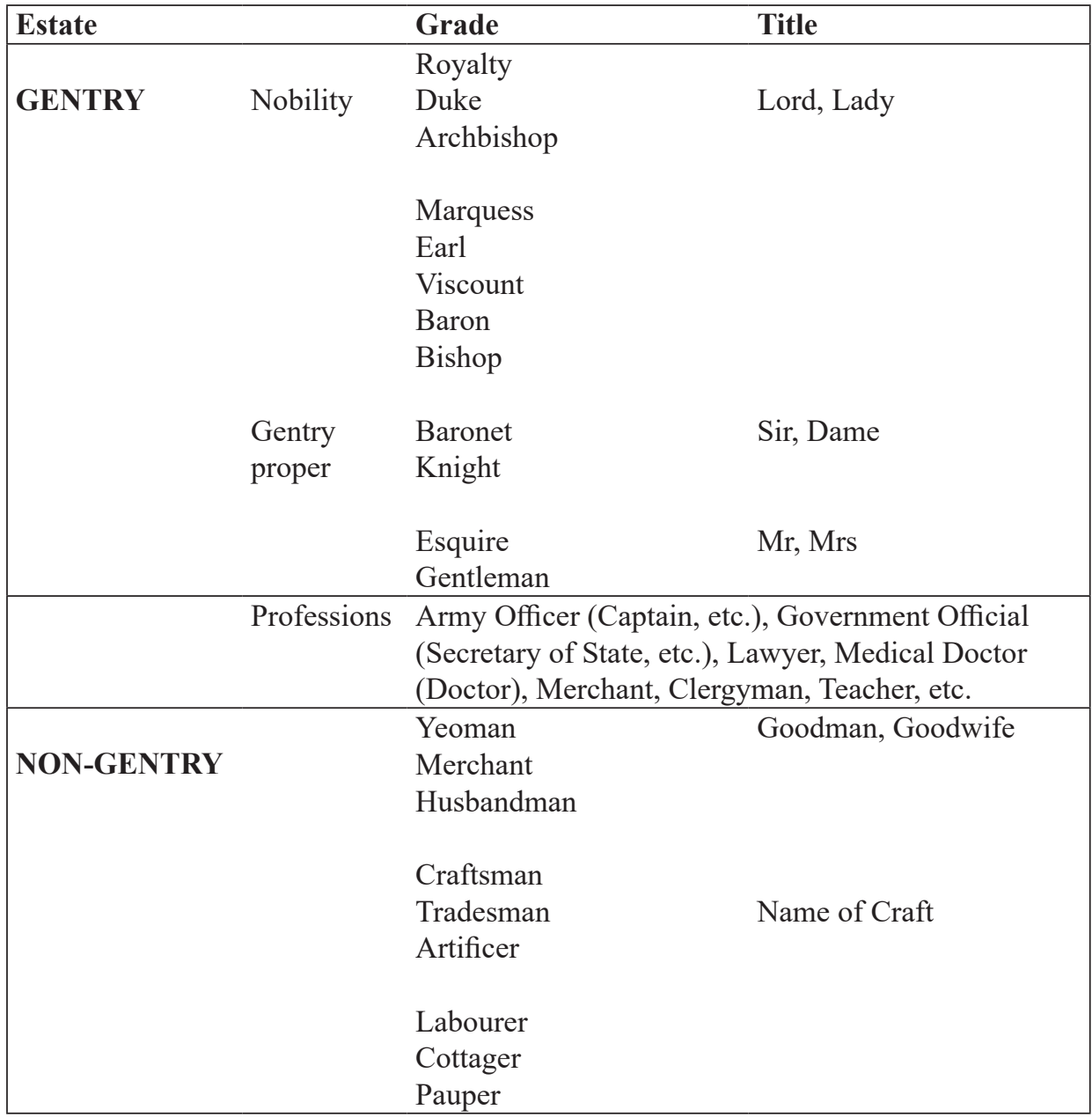

included in the group Royalty, whilst Gilbert Sheldon, identified as Archbishop of Canterbury, is included in the group Clergy. However, the presence of social ranks in the corpus is not equally represented inasmuch as the upper classes amount to $71 \%$ of informants due to the illiteracy of the lower classes. ${ }^{4}$ Table 2 reproduces the distribution of social ranks in the PCEEC as well as the distribution in terms of gender, providing the percentages of men and women, and the total figures of each social class. 
Table 2. Representation of informants in the PCEEC http://www.helsinki.fi/varieng/CoRD/corpora/CEEC/generalintro.html

\begin{tabular}{|lccc|}
\hline & Men & Women & Total \\
\hline Royalty & 2 & 6 & 3 \\
Nobility & 12 & 23 & 15 \\
Gentry & 35 & 56 & 39 \\
Clergy & 16 & 6 & 14 \\
Professionals & 14 & 4 & 11 \\
Merchants & 10 & 2 & 8 \\
Other non-gentry & 11 & 3 & 10 \\
Total & 100 & 100 & 100 \\
\hline
\end{tabular}

\subsection{Sociolinguistic analysis: results}

Considering the social stratification of the early Modern English period, a quantitative analysis has been carried out using the PCEEC as source of evidence in order to evaluate the use of the quasi-coordinator as well as in society. Figures have been normalized to tokens per 100,000 words for comparison.

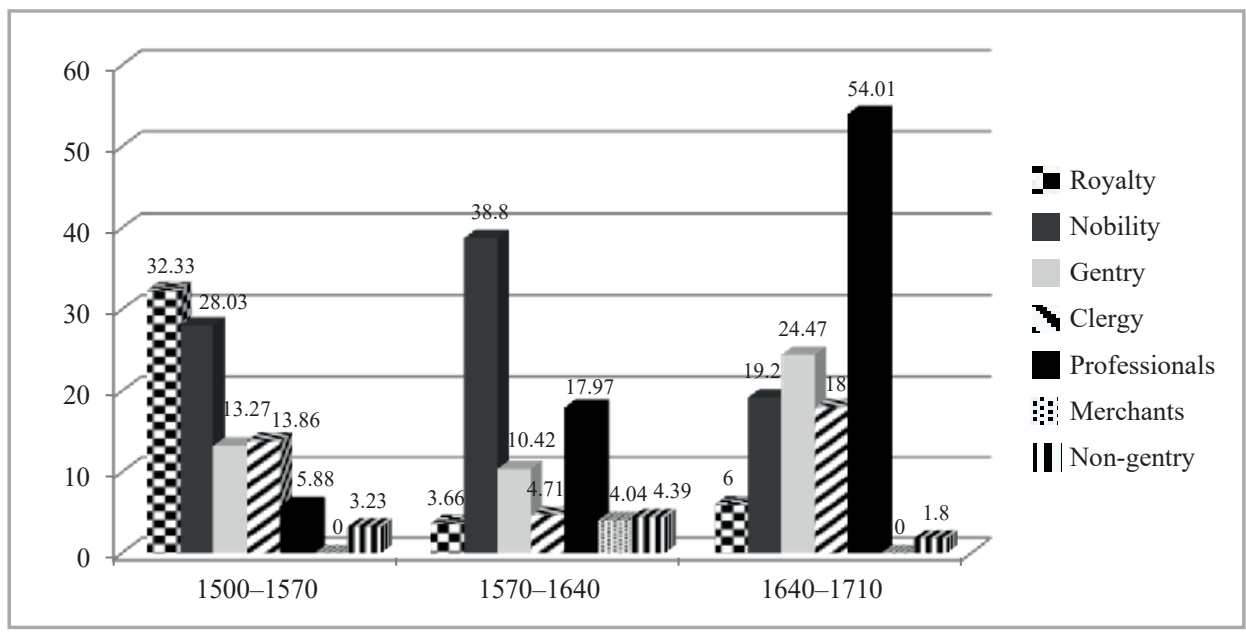

Figure 3. Distribution of as well as across social groups in early Modern English: 1500-1710 (n.f.)

Figure 3 shows the diffusion of as well as across the different social ranks of the period. In 1500-1570, the diffusion of this quasi-coordinator is led by the upper echelon, especially by the royalty (32.33) and the nobility (28.03), followed by the clergy (13.86) and the gentry (13.27). The use of this construction by the upper middle classes may be explained in terms of their closer contact with the highest social class. Keller (1994) identifies social success as a driving force behind language change, as noted in the royalty's and nobility's leadership in the 
diffusion of as well as. However, despite the high frequency of the upper ranks, this construction is already used by the members of the professional orders, although with a low rate of occurrence (5.88).

In the period 1570-1640, the nobility is still ahead in the spread of as well as (38.8). However, this quasi-coordinator has already been adopted by the professional group, who exhibits higher occurrences than the upper middle classes, contrary to what is observed in earlier periods. This is especially true for educated informants such as lawyers, scholars or writers, who were probably aware of the written forms of prestige in society and were willing to use them. Members of the professional group were also especially receptive to linguistic changes in written texts through their contact with legal documents (Conde-Silvestre and Calle-Martín 2015: 78). As this construction has a wider diffusion and reaches lower ranks, a sharp decrease in its use is witnessed among the members of the royalty (from 32.33 to 3.66 ), a behaviour that also coincides with other historical patterns. Labov (2001), for instance, studied changes from below among presentday English American speakers in relation to the socioeconomic status of informants, and observed a tendency for innovating elements to remain stable or even decline among their natural leaders, as noticed with the use of as well as among the members of the royalty.

In the period 1640-1710, the middle-lower ranks have already outnumbered the upper ones. This professional group has adopted the use of the quasi-coordinator to such an extent that the data show the highest rate of occurrences in the period (54.01). Interestingly enough, the adoption of this conjunction by the middle and lower ranks coincides with the highest number of occurrences of as well as in the community, becoming popular as its usage reaches a wider scope of population. The diffusion and adoption of this quasi-coordinator in society suggest that its development is probably a typical change diffusion from above, as the speakers are aware of the prestigious forms used by the upper strata and adopt them consciously. Changes from above "are introduced by the dominant social class, often with full public awareness [and] normally, they represent borrowings from other speech communities that have higher prestige in the view of the dominant class" (Labov 1994: 78). Examples of changes from above in early Modern English also include the disappearance of the multiple negation, or the rejection of the affirmative do due to its stigmatized social status (Nevalainen and Raumolin-Brunberg 2003; Nurmi 1999). They also occur in present-day English, as noted in the adoption of the (r)pronouncing norm among American speakers (Labov 2001). However, the upper strata are not always the leading innovating group and some changes may appear first in the vernacular and spread upwards from the lower social classes, although they seem to occur less frequently (Labov 1972).

Figures 4 and 5 reproduce the spread of the meanings (b) and (d) of as well as across the different social groups in the historical periods 1570-1640 and 16401710. The period 1500-1570 has been disregarded here due to the low number of occurrences of these two meanings before their spread in 1570 . 


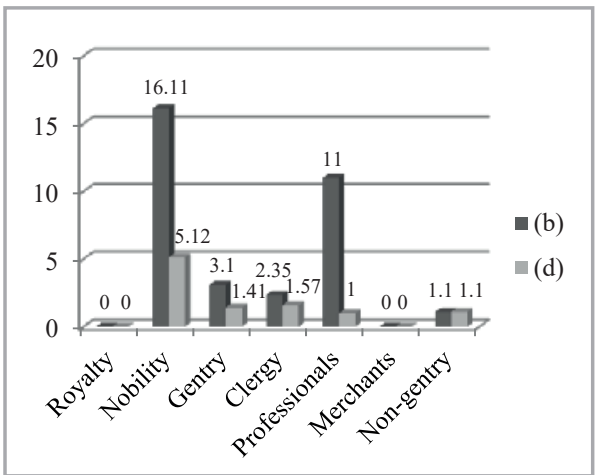

Figure 4. Diffusion of the meanings (b) and (d) in $1570-1640$ (n.f.)

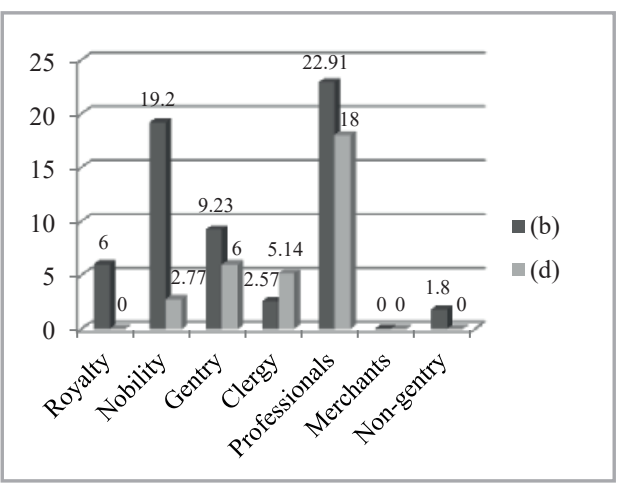

Figure 5. Diffusion of the meanings (b) and (d) in 1640-1710 (n.f.)

The diffusion of as well as with comparative function (b) and as a coordinating conjunction presenting the structure 'clause + as well as + clause' (d) across the different social ranks coincides closely with the general spread of this quasi-coordinator as shown in Figures 4 and 5. In the period 1570-1640, the highest rate is observed in the nobility (16.11 and 5.12, respectively), followed by the professional group. However, there are some differences in the use of as well as in the sense that all the social groups show a preference for its comparative function (b), suggesting that the diffusion of this construction might have been especially motivated by this meaning.

In the period 1640-1710, these two meanings have already been outnumbered by the professional orders, presenting the highest frequency at the time (22.91 and 18). Thus, the diffusion from above also entails the spread of the forms used by the nobility, since the professionals adopted this prestigious form among the members of the upper ranks. The data from the period show a preference for the comparative function (b), although as well as as a coordinating conjunction gained ground and increased in its use. Even though the differences between the use of the two functions are not significant, a slight preference for (b) is still witnessed in all the social groups with the exception of the clergy.

All this considered, it may be tentatively concluded that the proliferation of as well as after 1570 is probably caused by the adoption of two new functions of this quasi-coordinator: as well as with a comparative function relating or contrasting two elements (b), and as well as as a coordinator introducing new elements to a clause (d).

\section{Conclusions}

The present study has investigated the origin and grammaticalization of the quasi-coordinator as well as over time, examining the syntactic and semantic changes occurred. The second part of the analysis has considered the quantitative 
dimension of the construction over time in the Helsinki Corpus of English Texts (HC) and the Parsed Corpus of Early English Correspondence (PCEEC). From a chronological perspective, the process of grammaticalization has undertaken the following path: 1) the adverb well; 2) the sentence adverbial as well; and 3) the conjunction as well as. The genesis of the conjunction as well as thus stems from the Old English adverb well, an adverb of manner used to denote satisfactory or good way of performing an action.

The coexistence of the two lexical items in the historical period 850-950 eventually gave way to the sentence adverbial as well after a process of desemanticization by which it acquired a more abstract meaning, and as a consequence, it broadened the range of contexts in which this construction could be used.

The late Old English period witnessed a further process of grammaticalization which transformed the lexical sentence adverbial as well into as well as, then becoming a conjunction. One hundred years later, as well as became a comparative item, and this decategorization also implied a restriction in the freedom of movement of the construction, compelled to appear between the two linked elements, which are normally two NPs or two VPs. In the late $14^{\text {th }}$ century, as well as developed a new function as a coordinate conjunction connecting two elements at an equal semantic level. Two meanings stand out as a connector: a) as a conjunction, meaning 'and', 'both... and'; or b) as a marker of the introduction of a new element in the sentence (person, item, class, etc.). The first is syntactically represented as 'as well + clause + as + clause' whilst the latter is rendered as 'clause + as well as + clause'.

The syntactic changes that occurred during the process of grammaticalization are the result of a mechanism known as reanalysis. In the development of as well as, new syntactic functions are acquired without any superficial alterations in the construction. After this process, as well as becomes a quasi-coordinator acquiring the ability to behave as a subordinator in certain contexts, thus broadening its scope of movement as fronting is then also allowed.

The quantitative analysis has evaluated the development and diffusion of as well as over time, the late Middle English standing out as the key transitional period. While in Old English the coordinator as well as is characterized by a modest use, a substantial increase is observed towards the late $14^{\text {th }}$ century. The diffusion of this construction, especially from the early Modern English period, is led by two main functions: as well as as a comparative (b) and as well as as a coordinator represented as 'clause + as well as + clause' (d).

From a sociolinguistic perspective, the present study has correlated the use of the quasi-coordinator as well as with the reconstructed social structure of the early Modern English period adapted from Nevalainen and Raumolin-Brunberg (2003). The distribution of this construction reveals a change from above: the royalty and the nobility appear as the leaders of the diffusion of as well as, which later spread to the middle-lower ranks. In 1500-1570, the upper classes are ahead in the diffusion of this construction, however, its use is gradually adopted by the middle-lower ranks to such an extent that in the period 1640-1710 these members 
of society have already outnumbered the natural leaders of the change. The use of as well as is especially accepted by members of the professional orders who were aware of the prestige forms and were in contact with them through legal texts. In this sense, they consciously embrace these forms, which were eventually adopted by the lower members of society.

The present analysis has also attempted to correlate the different meanings and functions of the construction, focusing on the meanings (b) and (d). The social patterning reveals an outstanding preference for the comparative function of as well as, albeit an increase in the use of (d) is witnessed in 1640-1710.

\section{Notes}

1 The increment in the use of subordination was also a consequence of the influence of Latin and French stylistic devices (Fisher 1977).

2 It must be borne in mind that the concepts of coordination and subordination in earlier stages of the language were not as well-defined as in Present-day English.

3 The 1.5 million words of the HC are distributed as follows: Old English $(413,250)$, Middle English $(608,570)$ and early Modern English $(551,000)$.

$4 \quad$ "The socially unrepresentative character of historical texts is often due to the elite educational and social backgrounds of their authors. Members of lower social ranks and women are, as a rule, under-represented" (Kiełkiewicz-Janowiak 2012: 308).

\section{Sources}

Helsinki Corpus of English Texts (1991) Compiled by Rissanen, Matti, Merja Kytö, Leena Kahlas-Tarkka, Matti Kilpiö, Saara Nevanlinna, Irma Taavitsainen, Terttu Nevalainen and Helena Raumolin-Brunberg. Helsinki: University of Helsinki.

Oxford English Dictionary, 2nd edition (1989) Edited by Simpson, John A. and Edmund Weiner. [CD-Rom]. Oxford: Oxford University Press.

Parsed Corpus of Early English Correspondence, parsed version (2006) Compiled by Taylor, Ann, Arja Nurmi, Anthony Warner, Susan Pintzuk and Terttu Nevalainen. Helsinki: University of Helsinki and York: University of York.

\section{References}

Conde-Silvestre, Juan C. and Javier Calle-Martín (2015) Zero that-clauses in the history of English: A historical sociolinguistic approach (1424-1681). Journal of Historical Sociolinguistics 1 (1), $57-86$.

Fisher, John H. (1977) Chancery and the emergence of standard written English in the fifteenth century. Speculum 52 (4), 870-899.

Fischer, Olga, Anette Rosenbach and Dieter Stein (2000) Pathways of Change: Grammaticalization in English. Amsterdam and Philadelphia: John Benjamins.

Forbes, Clarissa (2014) On apparent nominal coordination in Gitksan. In: Teddiman, Laura (ed.) Proceedings of the 2014 Canadian Linguistic Association. St Catharines: Brock University. 
Giacalone-Ramat, Anna and Caterina Mauri (2011) The grammaticalization of coordinating interclausal connectives. In: Heine, Bernd and Heiko Narrog (eds.) The Oxford Handbook of Grammaticalization. Oxford: Oxford University Press, 656-666.

Haspelmath, Martin (2004) On directionality in language change with particular reference to grammaticalization. In: Fisher, Olga, Muriel Norde and Harry Perridon (eds.) Up and Down the Cline - The Nature of Grammaticalization. Amsterdam and Philadelphia: John Benjamins, 17-44.

Heine, Bernd and Kyung-An Song (2011) On the grammaticalization of personal pronouns. Journal of Linguistics 47 (3), 587-630.

Himmelmann, Nikolaus (2004) Lexicalization and grammaticalization: Opposite or orthogonal? In: Walter, Bisang, Nikolaus Himmelmann and Björn Wiemer (eds.) What Makes Grammaticalization: A Look from its Components and its Fringes. Berlin: Mouton de Gruyter, 21-44.

Hopper, Paul J. and Elizabeth C. Traugott (2003) Grammaticalization, $2^{\text {nd }}$ ed. Cambridge: Cambridge University Press.

Huddleston, Rodney and Geoffrey K. Pullum (2002) The Cambridge Grammar of the English Language. Cambridge: Cambridge University Press.

Huddleston, Rodney, John Payne and Peter Peterson (2002) Coordination and supplementation. In: Huddleston, Rodney and Geoffrey K. Pullum (eds.) The Cambridge Grammar of the English Language. Cambridge: Cambridge University Press, 1273-1362.

Jucker, Andreas H. (1997) The discourse marker well in the history of English. Language and Linguistics 1 (1), 91-110.

Keller, Rudi (1994) On Language Change: The Invisible Hand in Language. London: Routledge.

Kiełkiewicz-Janowiak, Agnieszka (2012) Class, age and gender-based patterns. In: Hernández-Campoy, Juan M. and Juan C. Conde-Silvestre (eds.) The Handbook of Historical Sociolinguistics. Oxford/ Malden: Wiley-Blackwell, 307-331.

Kim, Kyooshiek (2002) The number agreement of the English coordinated subjects. SNU Working Papers in English Language and Linguistics 1, 17-29.

Kohnen, Thomas (2007) 'Connectives profiles' in the history of English texts: Aspects of orality and literacy. In: Lenker, Ursula and Anneli Meurman-Solin (eds.) Connectives in the History of English. Amsterdam and Philadelphia: John Benjamins, 289-308.

Labov, William (1972) Sociolinguistic Patterns. Philadelphia: University of Pennsylvania Press.

Labov, William (1994) Principles of Linguistic Change: Internal Factors. Vol. 1. Oxford: Blackwell.

Labov, William (2001) Principles of Linguistic Change: Social Factors. Vol. 2. Oxford: Blackwell.

Langacker, Ronald W. (1977) Syntactic reanalysis. In Li, Charles N. (ed.) Mechanisms of Syntactic Change. Austin: University of Texas Press, 57-139.

Lass, Roger (1997) Historical Linguistic and Language Change. Cambridge: Cambridge University Press.

Lehmann, Christian (2004) Theory and method in grammaticalization. Zeitschrift für Germanistiche Linguistik 32 (2), 152-187.

Nevalainen, Terttu (2012) Historial Sociolinguistic. In: Bergs, Alexander and Laurel J. Brintol (eds.) English Historical Sociolinguistics: An International Handbook. Vol. 2. Berlin and Boston: Walter de Gruyter, 1438-1456.

Nevalainen, Terttu and Helena Raumolin-Brunberg (1996) Sociolinguistics and Language History: Studies Based on the Corpus of Early English Correspondence. Amsterdam and Atlanta: Rodopi.

Nevalainen, Terttu and Helena Raumolin-Brunberg (2003) Historical Sociolinguistics. Language Change in Tudor and Stuart England. London: Longman and Pearson Education.

Nurmi, Arja (1999) A Social History of Periphrastic 'do'. Helsinki: Société Néophilologique.

Quirk, Randolph, Sidney Greenbaum, Geoffrey Leech and Jan Startvik (1985) A Comprehensive Grammar of the English Language. New York: Longman.

Rissanen, Matti (1999) Syntax. In: Lass, Roger (ed.) The Cambridge History of the English Language. Vol. 3. Cambridge: Cambridge University Press, 187-331.

Ross, John R. (1967) Constraints on variables in syntax (Doctoral dissertation). MIT: Cambridge. 
Säily, Tanja (2014) Sociolinguistic Variation in English Derivational Productivity: Studies and Methods in Diachronic Corpus Linguistics. Helsinki: Mémoires de la Société Néophilologique. Traugott, Elizabeth C. (2010) Grammaticalization. In: Luraghi, Silvia and Vit Bubenik (eds.) Continuum Companion to Historical Linguistics. London: Continuum Press, 269-283.

Vázquez, Nila, Laura Esteban-Segura and Teresa Marqués-Aguado (2011) A descriptive approach to computerised English historical corpora in the 21st century. International Journal of English Studies 11 (2), 119-139.

\section{Appendix}

Table 3. Raw frequencies of as well as in the HC

\begin{tabular}{|ll|}
\hline $950-1050$ & 6 \\
$1050-1150$ & 2 \\
$1350-1420$ & 33 \\
$1420-1500$ & 33 \\
$1500-1570$ & 36 \\
$1570-1640$ & 34 \\
$1640-1710$ & 38 \\
\hline
\end{tabular}

Table 4. Raw frequencies of the distribution of as well as in the $\mathrm{HC}$

\begin{tabular}{|l|llll|}
\hline & (a) & (b) & (c) & (d) \\
\hline $950-1050$ & 5 & 1 & 0 & 0 \\
$1050-1150$ & 1 & 1 & 0 & 0 \\
$1350-1420$ & 0 & 6 & 22 & 5 \\
$1420-1500$ & 6 & 11 & 15 & 1 \\
$1500-1570$ & 1 & 10 & 25 & 0 \\
$1570-1640$ & 2 & 6 & 19 & 7 \\
$1640-1710$ & 3 & 16 & 6 & 13 \\
\hline
\end{tabular}

Table 5. Raw frequencies of the distribution of as well as across social groups

\begin{tabular}{|llllllll|}
\hline & Royalty & Nobility & Gentry & Clergy & Professionals & Merchants & Others \\
\hline $1500-1570$ & 2 & 13 & 16 & 6 & 2 & 0 & 1 \\
$1570-1640$ & 1 & 53 & 37 & 6 & 18 & 1 & 4 \\
$1640-1710$ & 1 & 16 & 53 & 14 & 33 & 0 & 1 \\
\hline
\end{tabular}

Table 6. Raw frequencies of the distribution of as well as across social groups and meanings (b) and (d)

\begin{tabular}{|c|c|c|c|c|c|c|c|c|c|c|c|c|c|c|}
\hline & \multicolumn{2}{|c|}{ Royalty } & \multicolumn{2}{|c|}{ Nobility } & \multicolumn{2}{|c|}{ Gentry } & \multicolumn{2}{|c|}{ Clergy } & \multicolumn{2}{|c|}{ Professionals } & \multicolumn{2}{|c|}{ Merchants } & \multicolumn{2}{|c|}{ Others } \\
\hline & (b) & (d) & (b) & (d) & (b) & (d) & (b) & (d) & (b) & (d) & (b) & (d) & (b) & (d) \\
\hline $1570-1640$ & 0 & 0 & 22 & 7 & 11 & 5 & 3 & 2 & 11 & 1 & 0 & 0 & 1 & 1 \\
\hline $1640-1710$ & 1 & 0 & 6 & 4 & 20 & 13 & 2 & 4 & 14 & 11 & 0 & 0 & 1 & 0 \\
\hline
\end{tabular}


MiRiam Criado-PeÑa is a Postgraduate Researcher at the University of Málaga, where she also collaborates as a research assistant with a project pursuing the electronic edition of hitherto unedited early Modern English scientific manuscripts. Her research interests lie within the fields of historical linguistics, manuscript studies and corpus linguistics.

Address: Miriam Criado Peña, Universidad de Málaga, Departamento de Filología Inglesa, Francesa y Alemana, Campus de Teatinos s/n, Málaga 29071, Spain. [email: mcriado@uma.es] 